\title{
Emission of Nitrogen Dioxide from Butane Gas Heaters and Stoves Indoors
}

\author{
Marwan Ghosn, Roula Flouty and Najat A. Saliba \\ Department of Chemistry, American University of Beirut, Beirut, Lebanon
}

\begin{abstract}
Levels of indoor nitrogen dioxide $\left(\mathrm{NO}_{2}\right)$ in a home equipped with butane gas stove and heaters are reported between the months of February and July 2003. Diffusion passive sampling was used for the simultaneous measurements of indoor and outdoor $\mathrm{NO}_{2}$ concentrations. The overall average indoor $\mathrm{NO}_{2}$ concentrations were 15.6 and $22.3 \mu \mathrm{g} \mathrm{m}^{-3}$ for the living room and kitchen, respectively, while that for outdoors was $17.9 \mu \mathrm{g} \mathrm{m}^{-3}$. In order to assess the input of indoor combustion to exchanged outdoor levels of $\mathrm{NO}_{2}$, the ratios of the living room and kitchen $\mathrm{NO}_{2}$ values to their corresponding outdoor levels were found to be higher in winter than in spring and summer. An $\mathrm{I} / \mathrm{O}$ ratio as high as 2.1 detected in winter was attributed to the excess use of butane gas heaters in both the kitchen and the living room. Other sources and fates of indoor $\mathrm{NO}_{2}$ are also evaluated. This study will have significant effects on estimating health risks related to the used of butane gas heaters in residential homes.
\end{abstract}

Key words: Indoor Nitrogen Dioxide, Butane Gas Heater, $\mathrm{NO}_{2}$ Derivatives, Developing Countries, Passive Sampling, Lebanon, Residential homes

\section{INTRODUCTION}

Indoor emission of $\mathrm{NO}_{2}$ from combustible appliances and heaters has been the focus of several studies due to its adverse health effects such as lung irritation, cough, respiratory illnesses and diarrhea [1-7]. Indoor levels of pollutants vary according to numerous factors including the use of different fuels for heating and cooking, outdoor concentrations, construction materials and meteorological conditions. In homes equipped with gas stoves, $\mathrm{NO}_{2}$ levels measured by passive sampling techniques varied from 10 to $126 \mu \mathrm{g} / \mathrm{m}^{3}$ [2, 8-18]. Values below $40 \mu \mathrm{g} / \mathrm{m}^{3}$ were mostly reported in Europe and the United States whereas upper levels, i.e. concentrations higher than $50 \mu \mathrm{g} / \mathrm{m}^{3}$, were measured in East Asia, e.g. Hong Kong [15], Japan [16] and Korea [8]. No data on $\mathrm{NO}_{2}$ indoor concentrations have been reported in the Middle East, up to our knowledge and studies conducted in East Asia, Europe and the United States cannot be extrapolated to Lebanon and the region for aspects such as housing characteristics, occupant behaviors and climate, differ. This study reports for the first time the levels and the seasonal variation of indoor $\mathrm{NO}_{2}$ concentration in Lebanon.

In this study, diffusion passive sampling is used to evaluate $\mathrm{NO}_{2}$ indoor air pollution in a home that employs butane gas stove and heaters, as well as the corresponding outdoor levels. Seasonal variations, as well as the effect of room characteristics on the change in indoor $\mathrm{NO}_{2}$ levels are determined. Evaluating the levels, sources and fates of indoor $\mathrm{NO}_{2}$ in Lebanon will have significant implications on assessing related health effects.

\section{MATERIALS AND METHODS}

Measurements of indoor and outdoor concentrations of $\mathrm{NO}_{2}$ have been carried out in an apartment of four occupants located on the second floor of an old building in the residential area of Broumana, Lebanon. The site is located about $700 \mathrm{~m}$ above sea level and $17 \mathrm{~km}$ driving distance away from the Mediterranean coast. It should be noted that smoking was nonexistent in the house during and outside sampling times. The sampling location is a poorly maintained residence with high ceiling $(3.5 \mathrm{~m})$, allowing relatively significant infiltration rates due to some flawed insulations. Cooking activities were based on the use of a butane gas stove with no fume hood, while heating relied entirely on two butane gas heaters, one in the kitchen and the other in the living room. Outdoor sampling took place on a balcony overlooking a street with light traffic pattern. Data will be divided into two sets: measurements up to the end of March characterize the winter season, while those reported between April and July represent spring and summer.

Diffusion Passive Samplers: Concentrations were determined by passive sampling technique which consisted of soaking glass fiber filters in triethanolamine (TEA) (10\% TEA and 4\% glycerol v/v in 10:33 v/v water:acetone) for the collection of gaseous $\mathrm{NO}_{2}$. All filter samplers used in the study were Osmonics ${ }^{\circledR}$ of $47 \mathrm{~mm}$ in diameter and 0.7 micron pore size. The glass membrane filters were stored in dark petri dishes to eliminate transmission of light until the time of analysis. Samples were individually soaked in 
$10 \mathrm{~mL}$ of deionized water and subsequently analyzed by the Griess reagent-colorimetric method. The Griess reagent $(2 \%$ sulfanilamide and $0.01 \% \quad \mathrm{~N}-1-$ naphthylethylenediamine dihydrochloride $\mathrm{w} / \mathrm{v}$ in $0.150: 1 \mathrm{v} / \mathrm{v}, 37 \% \mathrm{HCl}:$ water) was used for the determination of $\mathrm{NO}_{2}^{-}$: the absorbance of the obtained pink-purple azo complex $\left(\lambda_{\max }=540 \quad \mathrm{~nm}\right)$ was determined using Spectronic Genesys 2 UV-vis spectrophotometer. The herein calculated sampling rate of $1.073 \mathrm{~L} \mathrm{~min}^{-1}$ falls among the values reported for passive samplers with small thicknesses [19-22]. The average field blank value for the glass fiber membranes was found to be $0.60 \mu \mathrm{g} \mathrm{m}^{-3}$. Reproducibility of the method was tested by performing triplicate analyses for collected samples; the error $(2 \sigma)$ on several replicate measurements was determined as $1.50 \mu \mathrm{g} \mathrm{m}^{-3}$.

The samplers were positioned in three different locations: the living room, kitchen and balcony and collection duration extended for $24 \mathrm{~h}$. Samples were collected between the months of February and July 2003. The sampling sets in the living room and the kitchen were placed approximately $1.5 \mathrm{~m}$ above the ground surface and at least $1 \mathrm{~m}$ away from the closest window. The set for outdoor measurements was placed under a fixed table to avoid exposure to very high winds or contamination by rain droplets.

\section{RESULTS AND DISCUSSION}

Figure 1 shows the distribution of $\mathrm{NO}_{2}$ levels in the living room, kitchen and outdoors as well as the variation of these levels with respect to different seasons. The overall average indoor $\mathrm{NO}_{2}$ concentrations were 15.6 and $22.3 \mu \mathrm{g} \mathrm{m}^{-3}$ for the living room and kitchen, respectively, while that for outdoors was $17.9 \mu \mathrm{g} \mathrm{m}^{-3}$. Indoor reported levels compared well with countries like Germany [8, 11], Netherlands [10] and Canada [8]. In wintertime, indoor $\mathrm{NO}_{2}$ levels were twice as much as those found outdoors with concentrations reaching 27.6 and 31.1 in the living room and kitchen, respectively, while the outdoor concentration was $14.5 \mu \mathrm{g} \mathrm{m}^{-3}$. The highest level of $\mathrm{NO}_{2}$ measured $\left(53.1 \mu \mathrm{g} \mathrm{m}^{-3}\right)$ was recorded in the living room, during wintertime due to a butane gas heater burning continuously for over $8 \mathrm{~h}$. In the kitchen, even though two combustible sources; a butane gas stove and heater, were burning, the duration of operation was around half that of the single heater in the living room. In other seasons, indoor $\mathrm{NO}_{2}$ concentrations $(9.6$ and $17.9 \mu \mathrm{g} \mathrm{m}^{-3}$ for the living room and kitchen, respectively) were lower than values outside $\left(19.7 \mu \mathrm{g} \mathrm{m}^{-3}\right)$, due to a high air exchange rate through open doors and windows. Ventilation has been

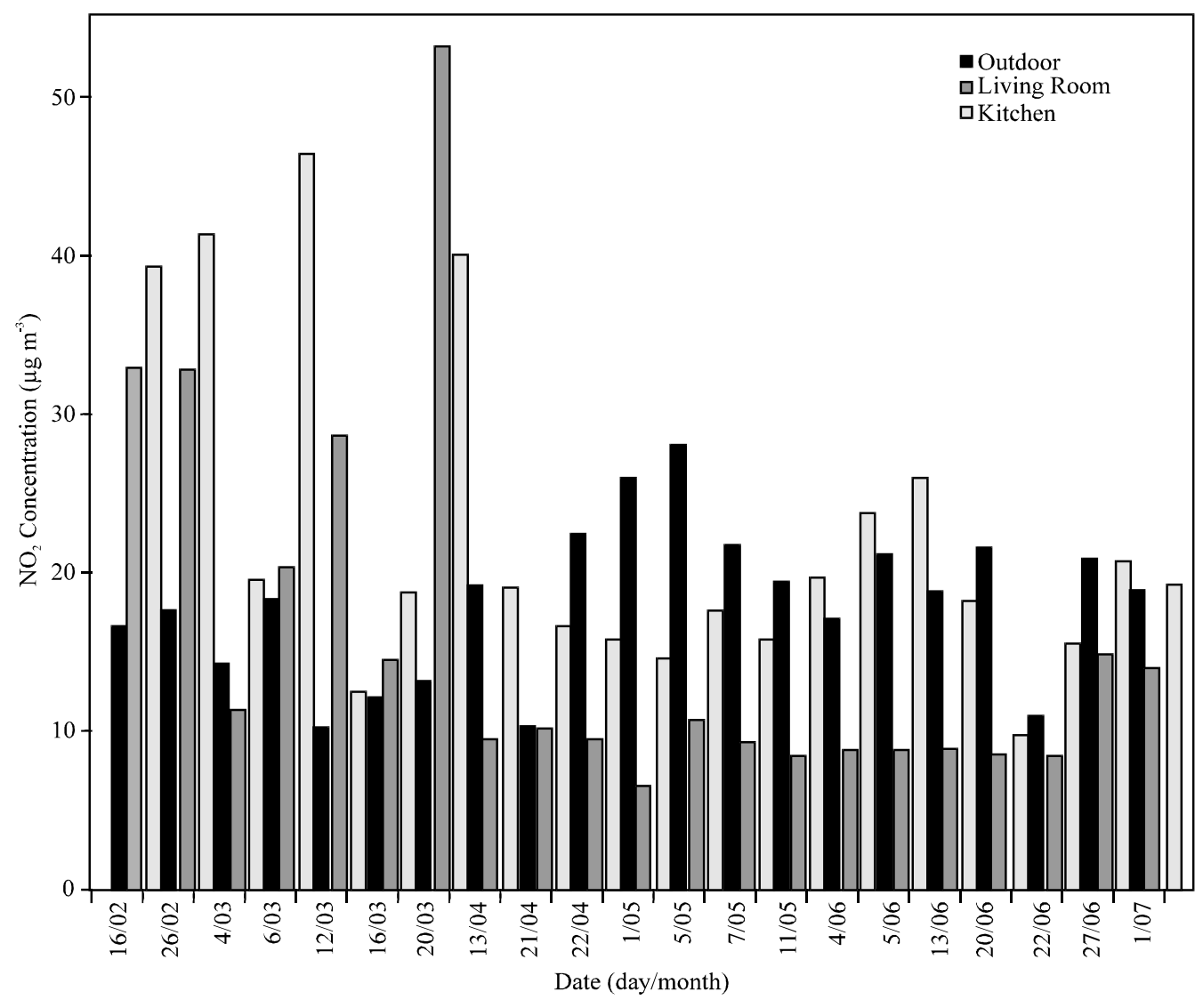

Fig. 1: Plot of Indoor and Outdoor $\mathrm{NO}_{2}$ Concentrations for a Residential Home in Broumana, Lebenon, Over the Winter, Spring and Summer Seasons Extending From February till July of 2003 
shown to play a major role in the reduction of indoor levels of pollutants [3, 9, 11, 14-16, 18, 23-26]. Outdoors, the samples measured a rural background where no industrial emission and a light traffic pattern explained the low reported $\mathrm{NO}_{2}$ concentrations. In view of the fact that smoking activity was absent, gas stoves and heaters were the only obvious sources of indoor $\mathrm{NO}_{2}$. Butane gas heaters seem to be a major source of indoor $\mathrm{NO}_{2}$, since a level four times higher than outdoors was still reached during the winter in the living room despite the fact that dilution of $\mathrm{NO}_{2}$ may have occurred due to the large size of the house and the air exchange via infiltration. In order to assess the contribution of gas heaters to infiltrated outdoor levels of $\mathrm{NO}_{2}$, the living room and kitchen $\mathrm{NO}_{2}$ values were divided by their corresponding outdoor $\mathrm{NO}_{2}$ concentrations ( $\mathrm{I} / \mathrm{O}$ ratios). The $\mathrm{I} / \mathrm{O}$ ratios were higher in winter than in spring and summer. In winter, an $\mathrm{I} / \mathrm{O}$ ratio of 2.1 was determined for both the living room and the kitchen whereas in spring and summer, I/O ratios of 0.53 and 1.0 were obtained for the living room and kitchen, respectively. The I/O ratio of 2.1 detected in the winter is attributed to the excess use of butane gas heaters in both the kitchen and the living room and to the slow air exchange rate with outdoors. This high I/O ratio compares well with Asian countries as suggested by Levy et al. [8] in addition to some sites in the Unites States, but diverge with respect to European and North American countries where different meteorological conditions, housing characteristics and/or higher outdoors pollution are expected [2, 8-13, $15-18,27,28]$. In spring and summer, a decrease in the $\mathrm{I} / \mathrm{O}$ ratio to 1.0 in the kitchen reflects both the decrease in $\mathrm{NO}_{2}$ emission due to the absence of the gas heater while cooking activities remained unchanged and the higher air exchange rate via open doors and windows, as shown clearly in Fig. 1. Although the same ventilation rate is anticipated in the living room due to similarities in the number and dimensions of the doors and windows as well as that the two room occupy the same facade, an even lower I/O ratio of 0.53 was determined. This is attributed to the absence of any combustible source and possibly to a reactive $\mathrm{NO}_{2}$ via homogeneous and heterogeneous reactions due to the presence of furniture.

Evaluating the concentration of $\mathrm{NO}_{2}$ indoors has several atmospheric and health implications. The knowledge in Lebanon and the Middle East is limited with regard to pollutant levels in indoor air. More alarming levels of $\mathrm{NO}_{2}$ are expected in Lebanese homes where smoking activity and combustibles such as diesel, kerosene, liquid gas and wood burning are prevalent.

\section{ACKNOWLEDGEMENTS}

This study was supported by the American University Research Board (URB) and the Lebanese National Council for Scientific Research (LNCSR).

\section{REFERENCES}

1. Farrow, A., R. Greenwood, S. Preece and J. Golding, 1997. Nitrogen dioxide, the oxides of nitrogen and infants' health symptoms. Arch. Environ. Health, 52: 189-196.

2. Gomzi, M., 1999. Indoor air and respiratory health in preadolescent children. Atmos. Environ., 33: 4081-4086.

3. Jones, A.P., 1999. Indoor air quality and health. Atmos. Environ., 33: 4535-4564.

4. Ponka, A. and M. Virtanen, 1994. Chronic bronchitis, emphysema and low-level air pollution in Helsinki,1987-1989. Environ. Res., 65: 207-217.

5. Beckett, W.S., M.B. Russi, A.D. Haber, R.M. Rivkin, J.R. Sullivan, Z. Tameroglu, V. Mohsenin and B.P. Leaderer, 1995. Effects of nitrous acid on lung infection in asthmatics: a chamber study. Environ. Health Perspectives, 103: 372-375.

6. Le Tertre, A., P. Quenel, D. Eilstein, S. Medina, H. Prouvost, L. Pascal, A. Boumghar, P. Saviuc, A. Zeghnoun, L. Filleul, C. Declercq and S. Cassadou, 2002. Short-term effects of air pollution on mortality in nine French cities: A quantitative summary. Arch. Environ. Health, 57: 311-319.

7. Keiding, L.M., A.K. Rindel and D. Kronborg, 1995. Respiratory illnesses in children and air pollution in Copenhagen. Arch. Environ. Health, 50: 200-206.

8. Levy, J.I., 1998. Impact of residential nitrogen dioxide exposure on personal exposure: An international study. J. Air and Waste Manage. Assoc., 48: 553-560.

9. Gallelli, G., P. Orlando, F. Perdelli and D. Panatto, 2002. Factors affecting individual exposure to $\mathrm{NO}_{2}$ in Genoa (northern Italy). Sci. Total Environ., 287: 31-36.

10. Janseen, N.A.H., P.H.N. van Vliet, F. Aarts, H. Harssema and B. Brunekreef, 2001. Assessment of exposure to traffic related air pollution of children attending schools near motorways. Atmos. Environ., 35: 3875-3884.

11. Cyrys, J., J. Heinrich, K. Richter, G. Wolke and H.E. Wichmann, 2000. Sources and concentrations of indoor nitrogen dioxide in Hamburg (west Germany) and Erfurt (east Germany). Sci. Total Environ., 250: 51-62. 
12. Monn, C., O. Brandli, C. Schindler, U. Ackermann-Liebrich, P. Leuenberger and S. Team, 1998. Personal exposure to nitrogen dioxide in Switzerland. Sci. Total Environ., 215: 243-251.

13. Spengler, J., M. Schwab, P.B. Ryan, S. Colome, A.L. Wilson, I. Billick and E. Becker, 1994. Personal exposure to nitrogen dioxide in the Los Angeles basin. J. Air and Waste Manage. Assoc., 44: 39-47.

14. Koussa, A., C. Monn, T. Rotko, S. Alm, L. Oglesby and M.J. Jantunen, 2001. Personal exposures to $\mathrm{NO}_{2}$ in the Expolis-study: relation to residential indoor, outdoor and workplace concentrations in Basel, Helsinki and Prague. Atmos. Environ., 35: 3405-3412.

15. Chao, C.Y.H., 2001. Comparison between indoor and outdoor air contaminant levels in residential buildings from passive sampler study. Build. Environ., 36: 999-1007.

16. Kodama, Y., K. Arashidani, N. Tokui, T. Kawamoto, K. Matsuno, N. Kunugita, N. Minakawa, 2002. Environmental $\mathrm{NO}_{2}$ concentration and exposure in daily life along main roads in Tokyo. Environ. Res., 89: 236-244.

17. Baek, S.O., Y.S. Kim and R. Perry, 1997. Indoor air quality in homes, offices and restaurants in Korean urban areas- indoor/outdoor relationships. Atmos. Environ., 31: 529-544.

18. Garcia-Algar, O., M. Zapater, C. Figueroa, O. Vall, X. Basagana, J. Sunyer, A. Freixia, X. Guardino and S. Pichini, 2003. Sources and concentrations of indoor nitrogen dioxide in Barcelona, Spain. J. Air and Waste Manage. Assoc., 53: 1312-1322.

19. Gillett, R.W., H. Kreibich and G.P. Ayers, 2000. Measurement of indoor formaldehyde concentrations with a passive sampler. Environ. Sci. Technol., 34: 2051-2056.
20. Shoeib, M. and T. Harner, 2002. Characterization and comparison of three passive air samplers for persistent organic pollutants. Environ. Sci. Technol., 36: 4142-4151.

21. Harner, T., N.J. Farrar, M. Shoeib, K.C. Jones and P.C. Gobas, 2003. Characterization of polymercoated glass as a passive air sampler for persistent organic pollutants. Environ. Sci. Technol., 37: 2486-2493.

22. Hofschreuder, P., W. van der Meulen, P. Heers and S. Slanina, 1999. The influence of geometry and draught shields on the preformance of passive samplers. J. Environ. Monit., 1: 143-147.

23. Dimitroulopoulou, C., M.R. Ashmore, M.A. Byrne and R.P. Kinnersley, 2001. Modelling of indoor exposure to nitrogen dioxide in the UK. Atmos. Environ., 35: 269-279.

24. Lee, S.C. and M. Chang, 2000. Indoor and outdoor air quality investigation at schools in Hong Kong. Chemosphere, 41: 109-113.

25. Kukadia, V. and J. Palmer, 1998. The effect of external atmospheric pollution on indoor air quality: A pilot study. Energy Buildings, 27: 223-230.

26. Vincent, D., I. Annesi, B. Festy and J. Lambrozo, 1997. Ventilation system, indoor air quality and health outcomes in Parisian modern office workers. Environ. Res., 75: 100-112.

27. Marbury, M.C., D.P. Harlos, J.M. Samet and J.D. Spengler, 1988. Indoor Residential $\mathrm{NO}_{2}$ Concentrations in Albuquerque, New Mexico. APCA, 38: 392-398.

28. Kousa, A., C. Monn, T. Rotko, S. Alm, L. Oglesby and M.J. Jantunen, 2001. Personal exposures to $\mathrm{NO}_{2}$ in the Expolis-study: Relation to residential indoor, outdoor and workplace concentrations in Basel, Helsinki and Prague. Atmos. Environ., 35: 3405-3412. 